\title{
CURRENT STATE OF THE ART HISTORIC BUILDING INFORMATION MODELLING
}

\author{
C Dore ${ }^{\mathrm{a}}$, M Murphy ${ }^{\mathrm{b}}$ \\ Dublin Institute of Technology, conor.dore@mydit.ie \\ bVBE Lab Ireland, virtualbuildinglab@gmail.com
}

\author{
Commission II, WG VI/4
}

\begin{abstract}
KEY WORDS: HBIM, Digital Heritage Documentation, Laser Scanning, Photogrammetry, Heritage Management, Procedural Modelling
\end{abstract}

\begin{abstract}
:
In an extensive review of existing literature a number of observations were made in relation to the current approaches for recording and modelling existing buildings and environments: Data collection and pre-processing techniques are becoming increasingly automated to allow for near real-time data capture and fast processing of this data for later modelling applications. Current BIM software is almost completely focused on new buildings and has very limited tools and pre-defined libraries for modelling existing and historic buildings. The development of reusable parametric library objects for existing and historic buildings supports modelling with high levels of detail while decreasing the modelling time. Mapping these parametric objects to survey data, however, is still a time-consuming task that requires further research. Promising developments have been made towards automatic object recognition and feature extraction from point clouds for as-built BIM. However, results are currently limited to simple and planar features. Further work is required for automatic accurate and reliable reconstruction of complex geometries from point cloud data. Procedural modelling can provide an automated solution for generating 3D geometries but lacks the detail and accuracy required for most asbuilt applications in AEC and heritage fields.
\end{abstract}

\section{INTRODUCTION}

\subsection{Overview}

The research reviewed in this paper shows the current state-ofthe-art for generating BIM geometry from point clouds and provides a context for the research that is to follow. This review covers the following range of topics within the sub sections:

2. Heritage Documentation Standards

3. Data Collection and Pre-Processing Techniques

4. 3D Modelling Concepts

5. As-Built BIM

Parametric Libraries

Automation for As-Built BIM

Quality Control for As-Built BIM

6. Procedural Modelling

\section{HERITAGE DOCUMENTATION STANDARDS}

Heritage documentation is the systematic collection and archiving of both tangible and intangible elements of historic structures and environments. The purpose of documentation is to supply accurate information that will enable correct conservation, monitoring and maintenance for the survival of an artefact (Eppich et al., 2007, Bryan et al., 2009). Examples of international and national standards for collecting and archiving information relating to historic structures are detailed in national guidelines such as the Historic American Building Surveys (HABS) and the English Heritage Metric Survey Practice (Balachowski, 2005, Bryan et al., 2009).

At an international level recording standards have been established by the International Council on Monuments and Sites (ICOMOS), which is an international non-governmental organisation of professionals, committed to the conservation of the world's historic monuments and sites (ICOMOS, 2012).
In the context of BIM, researchers at the Carleton Immersive Media Studio have carried out research on the development of standards for its use in heritage applications. A lot of effort is being made to establish standards for BIM within the AEC industry; however, this is even more challenging for heritage applications due to the complex and irregular nature of existing buildings. In an application of BIM for the documentation and management of the West Block of Canada's Parliament Hill, Fai and Rafeiro (2014) have established an appropriate level of detail (LoD) for as-built BIM projects. For this project, Fai \& Rafeiro (2014) suggest three levels of detail for effective longterm use which are based on the AEC Canada guidelines.

\section{DATA COLLECTION AND PRE-PROCESSING}

There are many surveying techniques available for acquiring data needed to generate accurate as-built Building Information Models. This includes the use of terrestrial laser scanning (TLS), photogrammetry and other traditional survey equipment such as total stations and GPS/GNSS equipment. A review of these techniques is outlined in this section.

\subsection{Terrestrial Laser Scanning}

Terrestrial laser scanning (TLS) is one of the most efficient methods of collecting data for accurate as-built modelling of buildings (Allen et al., 2003, Boehler and Heinz, 1999, Grussenmeyer and Hanke, 2010, Bernardini and Rushmeier, 2002). TLS can automatically record millions of threedimensional points on an object in near real time. TLS measures distances and angles from the sensor to an object being scanned with millimetre to centimetre accuracies possible. TLS operates on three different principals which are; triangulation, time of flight and phase comparison. All three types of laser scanners produce a 3D point cloud of the object. However, the range and accuracy capable from each method vary (Error! Reference source not found.). TLS provides an accurate, efficient and 
easy to use solution for acquiring $3 \mathrm{D}$ data required for as-built modelling of buildings. The main disadvantage of TLS for this application is the high cost of this technology.

\subsection{Photogrammetry}

Photogrammetry is the art and science of determining accurate measurements and three-dimensional data from photographs (Matthews, 2008). Photogrammetric techniques use images taken at different viewpoints to record the $3 \mathrm{D}$ geometry of a building or object. Photogrammetric techniques are becoming very popular for recording existing buildings, especially for cultural heritage applications. Low-cost digital cameras, powerful computer processing and the greater availability of commercial and open source photogrammetric software are driving many new applications for this technology (Beraldin, 2004). One of the main advantages of photogrammetry over laser scanning is the addition of high-quality imagery and colour information to the resulting data. The principles of photogrammetry are similar for both aerial and close range (ground based) photogrammetry. The main principles of photogrammetry are based on triangulation where lines of sight (rays) from two different camera locations are joined to a common point on the object. The intersection of these rays determines the three-dimensional location of the point. Using this technique with two images is known as stereo photogrammetry. When more than two images are used a bundle adjustment is used to simultaneously calculate all the unknown parameters. Although these techniques can be carried out with low-cost digital cameras, the entire process required can be cumbersome with a lot of processing time. The outputs from photogrammetric surveys are similar to the products obtained from laser scanning and include orthographic images, point clouds, triangulated surface models and also textured surface models.

\subsection{Pre-Processing Laser and Image Data}

Raw data acquired from terrestrial laser scanning (TLS) and close range photogrammetry (CRP) both require a number of pre-processing steps in order to generate products that can be used to create 3D CAD and BIM models. One of the main differences between TLS and CRP is that TLS automatically captures 3D point clouds directly while CRP requires postprocessing to generate $3 \mathrm{D}$ point clouds from images captured on site.

Even though TLS captures 3D point clouds directly a number of pre-processing steps are still required. Because most objects cannot be scanned from one single scan position, individual scans must be accurately combined and referenced together. This stage is called registration. This requires common targets or points to be identified in different scans. Developments in laser scan processing software have led to increased levels of automation for this step which includes automatic and semiautomatic target detection in separate scans. Research is also being carried out on full automatic techniques for registering laser scan point clouds (Theiler and Schindler, 2012, AKCA, 2003). Other pre-processing of TLS data include segmenting point clouds and filtering out unwanted data. Automatic triangulation of $3 \mathrm{D}$ points can also be carried out to create a mesh surface model from the $3 \mathrm{D}$ point cloud. This 3D mesh surface model can then be used to generate orthographic images by combining the $3 \mathrm{D}$ surface model with $2 \mathrm{D}$ images. $3 \mathrm{D}$ mesh models can also be textured using referenced image data. 2D cut sections and $3 \mathrm{D}$ vectors can also be generated from the $3 \mathrm{D}$ point cloud or 3D surface model.

Post processing for close range photogrammetry (CRP) varies depending on the number images. The main methods of processing include stereo processing and multi-convergent processing (bundle adjustment). Common processing stages required for both methods include selecting common feature points between images, calculating camera positions, orientations, distortions and reconstructing 3D information by intersecting feature point locations (Klein et al., 2012). Developments in computer vision and image matching algorithms have allowed for many of these steps to be carried out automatically. An example of an automated approach can be seen in work by Barazzetti et al. (2010). Although a lot of developments have been made towards full automatic post processing for close range photogrammetry, the accuracy and quality of the results of most automatic techniques cannot yet match the results of manual or semi-automatic procedures (Gruen, 2012). Using CRP for high accuracy as-built modelling would, therefore, require human interaction in the preprocessing of image data

\section{3D MODELLING CONCEPTS}

Advances in survey technology now allow for very fast and efficient data collection methods. Pre-processing of survey data is also becoming increasingly automated. 3D modelling from remotely sensed survey data is still, however, a manual and long process with much demand for new automated solutions. The evolution of current 3D modelling techniques from 2D/3D CAD to current 3D BIM solutions is reviewed in this section.

$3 \mathrm{D}$ modelling concepts have developed from early 2D and 3D $\mathrm{CAD}$ representations which were mainly composed of $2 \mathrm{D}$ or $3 \mathrm{D}$ lines. The first $3 \mathrm{D}$ wireframe models were an extension of $2 \mathrm{D}$ drafting where $3 \mathrm{D}$ lines were manually drawn to create a $3 \mathrm{D}$ wireframe model. This could be used for visualisation and to create orthogonal views. These early $3 \mathrm{D}$ wireframe models had no mass properties and it was not possible to add features such as holes. Two important advancements in 3D CAD modelling introduced in the 1970s and 1980s were the concepts Constructive Solid Geometry (CSG) and Boundary Representation (BREP). CSG uses solid primitive shapes to represent objects. This approach is more powerful than previous wireframe approaches as solid objects can be used to calculate various physical properties such as volume, density, weight and mass. CSG also allows solid primitive shapes to be combined using Boolean operations such as union, subtract and intersect to create more complicated shapes. Alternatively, Boundary Representation (BREP) represents objects by describing their faces, edges, vertices and topology. BREP also includes operations such as extrude, sweep and revolve which can be used to create 3D shapes from 2D outlines. Many CAD software platforms incorporate both BREP and CSG modelling concepts to provide greater flexibility for modelling complex objects.

3D shapes represented with CSG and BREP methods exist only as graphic entities and do not have intelligence (Ibrahim and krawczyk, 2004). The next evolutionary stage in 3D modelling was the introduction of parametric and feature-based modelling which introduced a certain amount of intelligence into model elements. Feature-based modelling is an object orientated approach where in addition to geometry, objects contain information about the objects role (e.g. door, wall, window etc.) and how an object relates to other objects. Feature-based modelling allows operations such as creating holes, fillets and chamfers to be associated with objects. This could include a 
window automatically cutting a hole when placed in a wall or intersecting walls connecting and joining correctly. Featurebased modelling enables objects to interact with other objects correctly and automatically in a spatial environment (Leeuwen and Wagter, 1997).

Parametric modelling differs from standard 3D CAD modelling as objects such as primitive shapes are associated with parameters or variables that can instantly change the geometry or other properties of an object. Simple parameters of an object may include an object's length, width, height or radius. Other more complex parametric objects may have parameters that can change the entire structure or geometry of an object depending on different conditions. Parameters of an object can also control the location of an object within a larger model. Parametric library objects (such as doors or windows) allow objects to be reused multiple times in a model or in many different models with varying parameters. This approach is very efficient for modelling elements that are repeated but may contain geometric variation between different instances.

The more recent development of the concept Building Information Modelling (BIM) incorporates the main developments in 3D modelling including parametric and feature-based modelling combined with a dynamic 3D database for storing information relating to buildings. The addition of a dynamic relational database for building elements (similar to a Geographic Information System) enables many new applications for managing and analysing building elements. BIM enables building elements to be documented with smart parametric reusable objects that contain rich information about the objects use, semantics, topology, relationships with other objects and further information stored as attributes. BIM can be defined as the assembling of parametric objects which represent building components within a virtual environment and which are used to create or represent an entire building. Objects are described according to parameters some of which are userdefined and others, which relate to its position in a 3D environment relative to other shape objects. The visualisation of objects is achieved through viewing $2 \mathrm{D}$ and $3 \mathrm{D}$ features, plans, sections, elevations and $3 \mathrm{D}$ views. BIM can automatically create cut-sections, elevations, details and schedules in addition to orthographic projections and 3D models (wireframe or textured and animated. All of these views are linked to the 3D model and automatically update in real time so if a change is made in one view, all other views are also updated. This enables fast generation of detailed documentation required in the AEC/FM and heritage industries.

\subsection{As-Built BIM}

The benefits of BIM make it a very suitable solution for modelling and managing information relating to existing buildings. A BIM for an existing or historical building can be used as a documentation and management tool for conservation work, retrofitting, renovations and building analysis. The concept of an as-built BIM is being used to describe the recording of existing buildings with BIM. This includes both an 'as-built' representation (recording of a building after construction) and an 'as-is' representation (recording a current condition of a building). This process involves three main stages; data acquisition, pre-processing of survey data and a modelling stage. Due to the fact that an as-built BIM is generated from survey data, Hichri et al. (2013) define an asbuilt BIM as a building described with a BIM representation at the moment of survey.

Volk et al. (2014), Hichri et al. (2013) and Tang et al. (2010) provide excellent and comprehensive overviews on the current state-of-the-art in the area of as-built BIM. The fundamental problems outlined in these reviews are the "high modelling/conversion effort" required for creating semantic BIMs from unstructured survey data, the difficulties in accurately representing the variety of complex and irregular objects occurring in existing buildings and the lack of standards for the representation of objects and information in existing buildings.

A lot of developments for as-built BIM are emerging from the adoption of BIM from cultural heritage communities. Many authors have shown the benefits of using BIM for cultural heritage preservation (Fai et al., 2011, Oreni et al., 2014, Wu et al., 2013, Boeykens et al., 2012, Pauwels et al., 2008, Quattrini et al., 2015, Barazzetti et al., 2015). Pauwels et al. (2008) describe an approach called Architectural Information Modelling which uses BIM to document geometric data along with appended historical information such as photographs, scanned documents or research material. Fai et al. (2011) adopt a similar approach which links heritage information to a BIM but also includes documentation related to tangible and intangible heritage. Boeykens et al. (2012) use BIM software to create a reconstruction of the Vinohrady Synagogue in Prague which was demolished in 1951. The authors of this paper note that the BIM software used was almost completely focussed on contemporary buildings and that more specific tools are needed for historical reconstructions. Another development emerging from the cultural heritage community is a plug-in to Autodesk Revit BIM called "GreenSpider" (Garagnani and Manferdini, 2013). This plug-in improves the current process for importing unstructured datasets into BIM software by translating key points from the point cloud into native reference snaps in Revit.

\subsection{Parametric Libraries}

Most BIM software packages have extensive libraries of predefined parametric objects that are used to create 3D building information models. This facilitates efficient modelling as 3D geometry does not have to be created from scratch. Instead existing information enhanced library objects can be used to model the main building elements such as walls, doors, windows, columns, beams, slabs, roofs etc. Parameters of these library objects are edited to match the required dimensions and settings of a project. These library objects are then combined to create a complete model. A major problem for as-built BIM is the lack of pre-defined parametric objects suitable for existing and historical buildings. Most native and $3^{\text {rd }}$ party BIM libraries are focused only on modern buildings. As a result, modelling existing and historic buildings often require many bespoke components to be created from scratch which can be a very time-consuming process.

This limitation of BIM for existing buildings has motivated research in the development of new parametric libraries that would be suitable for existing and historic buildings. Various projects (Baik et al., 2014, Chevrier et al., 2010, Fai and Rafeiro, 2014, Murphy et al., 2013, De Luca, 2012) have shown that the development of new reusable parametric library objects supports high levels of detail (LoD) while decreasing the time of modelling. The parametric objects created by Fai \& Rafeiro (2014) were created for the Autodesk Revit BIM software and contain very useful objects representing gothic style architectural windows. The library created by Baik et al. (2014), also for Autodesk Revit BIM software, contains parametric objects for heritage projects in the Al-Balad district of Jeddah City. An extensive library of parametric objects was created by Chevrier et al. (2010). However, these objects are not suitable 
for BIM and were instead created with the MEL scripting language for Autodesk Maya software.

Work from Murphy et al. (2013) has led to the development of a new library of parametric objects for BIM software called Historic Building Information Modelling (HBIM) (Error! Reference source not found.). These new library objects are designed for modelling classical architectural elements found in many existing buildings. The parametric architectural objects are designed from historic manuscripts and architectural pattern books and are implemented using an embedded programming language within the ArchiCAD BIM software called the Geometric Description Language (GDL). Also included with this library of objects is a system for mapping objects to survey data.

\section{AUTOMATION FOR AS-BUILT BIM}

Automated modelling of existing buildings from scan data is very desirable commercially to reduce time and therefore costs of as-built BIM projects (Thomson and Boehm, 2015). One area where progress is being made towards automated as-built BIM is in automated object recognition and feature extraction from point clouds (Jung et al., 2014, Xiong et al., 2013, Zhang and Zakhor, 2014). Object recognition is the problem of automatically labelling data points or segments of an image with a named object or object class (Tang et al., 2010), for example automatically detecting windows or doors from an image or point cloud. Once objects are automatically recognised from a dataset, primitives or planes can be automatically fitted to the recognised elements in the dataset. A lot of the research in this area, however, is focused on indoor applications (Jung et al., 2014, Previtali et al., 2014, Zhang and Zakhor, 2014, Thomson and Boehm, 2015) and is currently restricted to automatic extraction of basic elements such as planes and openings. Automatic extraction of complex architectural elements that occur in existing and historical buildings is still in its infancy.

$\mathrm{Pu} \&$ Vosselman (2009) is one example of object recognition applied to building applications. In this work a knowledgebased approach for object recognition is adopted which aims to automatically reconstruct building facades from terrestrial laser scan data. Point clouds obtained from terrestrial laser scanning are first automatically segmented into planar surfaces which are then automatically classified as semantic features such as walls, doors, windows and roofs using generic knowledge of building facades. This includes knowledge about a features size, position, orientation and topology. Next, an outline polygon is generated for each detected feature using least square fitting, convex hull fitting or concave polygon fitting Finally building knowledge is again used to make assumptions for missing or occluded areas. Results of this automatic object recognition approach include a polygon model for detected building features.

Much of the existing work for automated object recognition and feature detection show promising results but do not automate the complete process from point cloud to BIM (Hong et al., 2015, Jung et al., 2014, Xiong et al., 2013, Zhang and Zakhor, 2014, Wang et al., 2015). The results from these automatic approaches include surface models, planes, 3D vectors or a subset of the original point cloud, all of which still need to be converted into structured information enhanced and parametric BIM components which at present needs to be carried out manually (Volk et al., 2014, Thomson and Boehm, 2015). The results from Hong et al. (2015) are regularised wireframe models which are automatically detected from point clouds for indoor building applications. These simplified wireframe models are then used for geometric modelling with BIM software instead of the original point cloud. Two case studies testing this approach showed that the efficiency of the as-built BIM creation process was improved by $15.4 \%$ and $15.0 \%$ using the extracted wireframe models instead of the complete point cloud (Hong et al., 2015).

Thomson and Boehm (2015) is one of the few examples of automated object detection and feature extraction from point clouds resulting in object-based IFC models, suitable for BIM. This approach utilises the open source Point Cloud Library (PCL) which provides a number of data handling and processing algorithms such as a RANSAC (RANdom SAmple Consensus) algorithm for automatic plane detection. The eXtensible Building Information Modelling (xBIM) toolkit, which is capable of reading and writing IFC compliant files, is used to create IFC content from detected features. While this work shows excellent progress for the automatic reconstruction of BIM geometry from point clouds, the work currently only deals with planar walls and is limited in terms of accuracy and reliability.

In conjunction with these developments in research, commercial software is also emerging in recent years which attempts to automate and improve existing manual workflows for the generation of BIM geometry from point clouds. This includes plug-ins to Autodesk Revit software, Trimble SketchUp software and standalone software such as Pointfuse from Arithmetica. Currently, none of these commercial software solutions are capable of fully automating the as-built BIM process but do offer various semi-automatic solutions and tools which improve the efficiency of certain stages of the process. ClearEdge3D offer a standalone software platform called EdgeWise Building in addition to a plug-in to Autodesk Revit BIM software. This software classifies a point cloud into surfaces that share coplanar points. The operator then picks floor and ceiling planes to constrain the search for extracting wall features. Once wall planes are detected the Revit plug-in creates the parametric object-based wall geometry. Another plug-in has been developed for Autodesk Revit software by IMAGINiT called Scan to BIM. This plug-in provides detection and fitting algorithms for planes and cylinders to create walls, pipes and column objects. With this approach, a user picks three points to define a wall plane and a region growing algorithm detects the extents of the wall. The user then selects a tolerance and the type parametric wall element to be used in the model (Thomson and Boehm, 2015).

Kubit, now owned by Faro also provide a plug-in to Autodesk Revit that detects planes for creating wall objects along with providing tools that aid the manual process of tracing points in a point cloud. Pointfuse from Arithmetica provides standalone software which can automatically detect planes and edges from a point cloud and export these in standard CAD formats. Trimble also provides an extension for their SketchUp software that can detect planes with a semi-automatic process.

These developments emerging from academic research and in commercial software platforms show progress towards automating the as-built BIM process. However, these automatic methods to date are limited to extracting simple planar features. Very little progress has been made at automatically reconstructing complex and non-planar geometry that often occurs in existing and historical buildings. Attempts at the automatic recognition of objects and feature detection are focused on indoor scenes tend to work well only in simple and uncluttered environments. Other more complicated environments containing clutter and occlusion can result in less accurate and reliable results. Automatic object recognition and detection approaches can result in errors such as objects being incorrectly segmented and classified, objects not being 
classified or detected, incorrect object fitting and incorrect assumptions for occluded or missing data. Case studies from $\mathrm{Pu}$ \& Vosselman (2009) and Thomson and Boehm (2015) show discrepancies in certain areas of ten centimetres or more between the automatically detected features and the scan data. Unfortunately, this is not currently at the level of accuracy and reliability required for most documentation projects in the AEC and heritage fields. Further work is needed to achieve higher accuracy results required for such applications.

\section{QUALITY CONTROL FOR AS-BUILT BIM}

For many applications of as-built BIM, it is crucial that the model accurately represents the true condition of a building. This is particularly important when BIM is used to produce documentation for conservation work, restorations, retrofitting or performing different types of building analysis. The workflows for creating as-built BIMs also involve several steps that can be subjective in nature when carried out manually so inadvertent errors can easily be introduced. Whether an as-built BIM is created manually or using automatic techniques it is very important that quality assurance $(\mathrm{QA})$ is carried out to ensure the accuracy of the final model. (Anil et al., 2011, Anil et al., 2013) propose a new approach for QA of as-built BIM that analyses patterns of the geometric deviation between the model and the point cloud data. This research demonstrates that it is possible to identify the source, magnitude, and nature of errors by analysing the deviation patterns. This proposed deviation analysis involves computing the deviations by finding correspondences between point cloud and BIM and then computing the distances between correspondences. Next, the deviations are visualised with colour-coded maps of the deviations. Finally, deviation maps are inspected and potential errors are identified and verified. In comparison to other QA approaches of using a sample of physical measurements or ground truths the deviation analysis method provides full coverage and can provide deterministic guarantees that a model completely represents the underlying data with a given accuracy specification.

\section{PROCEDURAL MODELLING}

Another automated approach to 3D modelling which has currently not been adopted or implemented for as-built BIM is procedural modelling. Procedural modelling is an automated approach to generating 3D content based on a sequence of generation instructions, rules or algorithms that can be repeated with varying characteristics (Kelly and Mccabe, 2006). Procedural modelling has traditionally been used in applications such as film and gaming where content can be randomly generated based on rules and algorithms. The use of shape grammars in procedural modelling has gained a lot of interest and is now being used to generate content for architectural modelling (Muller et al., 2006, Dylla et al., 2010, Hohmann et al., 2009, Becker and Haala, 2009, Becker et al., 2015). Shape grammars originally introduced by Stiny and Gips (1972) are derived from formal grammars and consist of a set of basic vocabulary shapes (terminals and non-terminals) and a set of production rules to transform these shapes to create $3 \mathrm{D}$ content. A shape grammar called CGA Shape (Muller et al. 2006) has been developed for the commercial software CityEngine from ESRI. This shape grammar is designed for procedural modelling of buildings and cities. CityEngine software provides users with tools to create 3D content from scripts using this shape grammar. With this software, it is possible to procedurally generate buildings from 2D footprints and other GIS datasets for modelling existing buildings and cities. While these models contain information about semantics and can be automatically generated, they lack the detail that would be required for applications in the AEC/FM and heritage communities.

Most procedural modelling applications require users to code rules in a grammar to create a model. This text-based approach restricts users with little computer science background. Work by Lipp et al. (2008) has concentrated on creating an interactive visual editing tool for shape grammars to create rules from scratch without the need for text file editing. This makes automated approaches for generating 3D content much more accessible and does not require advanced users to create scripts to code rules.

Another approach (Müller et al., 2007) uses the CGA shape grammar for automatic modelling of existing building facades from a single rectified image. This method automatically detects a façade structure using mutual information and symmetry detection to divide a façade into floors and tiles. Further tile refinement is automatically carried out using edge detection to split tiles into smaller regions using a subdivision concept from procedural modelling which creates a hierarchy of elements. This is used to automatically detect window positions, ledges and window sills. 3D objects from a library of architectural elements are then matched to the subdivided façade to add windows and other architectural elements. Depth for different sections of the façade is added manually and the computed façade can be exported as shape grammar rules in the CGA Shape Grammar. This method shows how procedural modelling techniques can be applied to existing buildings. This method works well for urban environments where facades contain a lot of repetition and symmetry can be easily detected. However less repetitive facades with a lot of architectural detail may be problematic for this automatic method.

Other work by Hohmann et al. (2009) use shape grammars to automatically model building facades for automatic 3D city reconstruction. This project called "CityFit" aims to reconstruct $80 \%$ of the buildings in the city of Graz fully automatically. Their workflow uses roadside photographs and LiDAR point clouds as input data. Image based feature detection is carried out to detect and segment windows, arches and other decorative elements. Depth maps derived from the point cloud are also used to provide depth information. The results from these segmentations are matched against a set of shape grammar templates obtained by façade analysis and classification. The use of shape grammar templates in the modelling stage incorporates architectural knowledge to automate this stage. The shape grammars and shape grammar templates used are based on the concepts of the CGA shape grammar but have been implemented using the Generative Modelling Language (GML).

A procedural modelling approach with shape grammars has many advantages such as automatic generation, great flexibility for variation, object hierarchy, scalable geometric representation and data handling of large models. However, a disadvantage of these methods for AEC and heritage applications is that they are inefficient at generating smaller complex geometric detail. Muller et al. (2006), state that manual methods are used instead of procedural modelling techniques to create detailed elements such as roof bricks, capitals and window grills. The main application of procedural modelling applied to existing buildings to date has been for visualisation. In the reconstruction of existing building facades, Müller et al. (2007) state that the generated models are primarily for visualisation and the aim is to automatically create a geometric model that "looks like a plausible interpretation of the input image". For AEC and heritage applications, a more precise and accurate 
model is required. Current software for procedural modelling also does not automate the production of engineering drawings which is critical for most applications in the AEC and heritage sectors.

\section{CONCLUSIONS OF REVIEW}

In this paper, a critical review of existing work was carried out on the main topics involved in this research project. After carrying out an extensive review of existing literature a number of observations were made in relation to the current state-of-theart and limitations of different approaches for recording and modelling existing buildings and environments:

1. Data collection and pre-processing techniques are becoming increasingly automated to allow for near real-time data capture and fast processing of this data for later modelling applications.

2. Current BIM software is almost completely focused on new buildings and has very limited tools and pre-defined libraries for modelling existing and historic buildings.

3. The development of reusable parametric library objects for existing and historic buildings supports modelling with high levels of detail while decreasing the modelling time. Mapping these parametric objects to survey data, however, is still a timeconsuming task that requires further research.

4. Promising developments have been made towards automatic object recognition and feature extraction from point clouds for as-built BIM. However, results are currently limited to simple and planar features. Further work is required for automatic accurate and reliable reconstruction of complex geometries from point cloud data.

5. Procedural modelling can provide an automated solution for generating 3D geometries but lacks the detail and accuracy required for most as-built applications in AEC and heritage fields. The main applications of procedural modelling include visualisation for film or gaming. Existing procedural modelling implementations also do not automate the production of engineering drawings for construction or conservation documentation.

\section{REFERENCES}

Akca, D. 'Full Automatic Registration of Laser Scanner Point Clouds', Optical 3D Measurement Techniques, VI, Zurich Switzerland, 22-25 September 2003, 330-337.

Allen, P. K., Troccoli, A., Smith, B., Murray, S., Stamos, I. and Leordeanu, M. (2003) 'New Methods for Digital Modeling of Historic Sites', IEEE Comput. Graph. Appl., 23(6), pp. 32-41.

Anil, E. B., Tang, P., Akinci, B. and Huber, D. 'Assessment of the quality of as-is building information models generated from point clouds using deviation analysis'. 78640F-78640F-13.

Anil, E. B., Tang, P., Akinci, B. and Huber, D. (2013) 'Deviation analysis method for the assessment of the quality of the as-is Building Information Models generated from point cloud data', Automation in Construction, 35(0), pp. 507-516.

Baik, A., Alitany, A., Boehm, J. and Robson, S. (2014) 'Jeddah Historical Building Information Modelling "JHBIM" - Object Library', ISPRS Ann. Photogramm. Remote Sens. Spatial Inf. Sci., II-5, pp. 41-47.
Balachowski, D. J. (2005) HABS Guidelines, Recording Historic Structures, and Sites with HABS Measured Drawings.

Barazzetti, L., Scaioni, M. and Remondino, F. (2010) 'Orientation and 3D modelling from markerless terrestrial images: combining accuracy with automation', The Photogrammetric Record, 25(132), pp. 356--381.

Barazzetti, L., Banfi, F., Brumana, R., Gusmeroli, G., Oreni, D., Previtali, M., Roncoroni, F. and Schiantarelli, G. (2015) 'BIM from Laser Clouds and Finite Element Analysis: Combining Structural Analysis And Geometric Complexity', Int. Arch. Photogramm. Remote Sens. Spatial Inf. Sci., XL-5/W4, pp. 345-350.

Barber, D. and Mills, J. (2007) 3D Laser Scanning for Heritage: Advice and guidance to users on laser scanning in archaeology and architecture: English Heritage.

Beacham, R., Niccolucci, F. and Denard, H. (2009): The London Charter. London. Available at: http://www.londoncharter.org/.

Becker, S. and Haala, N. 'Grammar Supported Facade Reconstruction from Mobile Lidar Mapping '. CMRT09 CityModels, Roads and Traffic, Paris, France, 3 - 4 Spetember 2009: The International Archives of the Photogrammetry, Remote Sensing and Spatial Information Science.

Becker, S., Peter, M. and Fritsch, D. (2015) 'GrammarSupported 3D Indoor Reconstruction From Point Clouds For "As-Built" BIM', ISPRS Ann. Photogramm. Remote Sens. Spatial Inf. Sci., II-3/W4, pp. 17-24.

Beraldin, J. A. (2004) 'Integration of Laser Scanning and CloseRange Photogrammetry - Last Decade and Beyond', XXth International Society for Photogrammetry and Remote Sensing (ISPRS) Congress Istanbul, Turkey, July 12-23, 972-983.

Berlo, L. v. and Laat, R. d. 'Integration of BIM and GIS: The Development of the CityGML GeobBIM Extension', 5th International 3D GeoInfo Conference, November 3-4, 2010, Berlin, Germany, Berlin, Germany.

Bernardini, F. and Rushmeier, H. (2002) 'The 3D Model Acquisition Pipeline', Computer Graphics Forum, 21(2), pp. 149-172.

BIMobject (2016) BIMscript \& LENA. Available at: http://info.bimobject.com/bimscript 2016).

Boehler, W. and Heinz, G. 'Documentation, Surveying, Photogrammetry', XVII CIPA Symposium, Olinda, Brazil, 3rd 6th October 1999.

Boeykens, S. (2011) 'Using 3D Design software, BIM and game engines for architectural historical reconstruction '. CAAD Futures 2011, Liège, Belgium, 6-8 July 2011.

Boeykens, S., Himpe, C. and Martens, B. (2012) 'A Case Study of Using BIM in Historical Reconstruction - The Vinohrady synagogue in Prague'. The 30th International Conference on Education and research in Computing Aided Architectural Design in Europe, Prague, Czech Republic, 12-14 September 2012. 
Boloix, G. (1997) 'System evaluation and quality improvement', J. Syst. Softw., 36(3), pp. 297-311.

Boloix, G. and Robillard, P. N. (1995) 'A software system evaluation framework', Computer, 28(12), pp. 17-26.

Borenstein, D. (1998) 'Towards a practical method to validate decision support systems', Decision Support Systems, 23(3), pp. 227-239.

Bryan, P., Blake, B., Bedford, J., Barber, D., Mills, J. and David, A. (2009) Metric Survey Specifications for Cultural Heritage: English Heritage.

Byrne, C. (2015) 'Restored Four Courts dome set for seal of approval', The Irish Times, 7th December 2015. Available at: http://www.irishtimes.com/news/ireland/irish-news/majordomo-1.2456337.

Carroll, J. M. (2000) Making use: scenario based design of human-computer interactions. Cambridge: The MIT Press.

Cashman, J. 1922a. The Four Courts Bombardment (1922). In:RTÉ Cashman Collection.

Cashman, J. 1922b. The Four Courts Damage (1922). In:RTÉ Cashman Collection.

Centofanti, M., Continenza, R., Brusaporci, S. and Trizio, I. 'The architectural information system SIARCH3D-UNIVAQ for analysis and preservation of architectural heritage', 4th ISPRS International Workshop 3D-ARCH 2011: "3D Virtual Reconstruction and Visualization of Complex Architectures", Trento, Italy, 2-4 March 2011, 9-14.

Chevrier, C., Charbonneau, N., Grussenmeyer, P. and Perrin, J.P. (2010) 'Parametric Documenting of Built Heritage: 3D Virtual Reconstruction of Architectural Details', International Journal of Architectural Computing, 08(02), pp. 131-145.

CIPA (2010) The International Committee for Documentation of Cultural Heritage Heritage Documentation. Available at: http://cipa.icomos.org/ (Accessed: October 2015).

De Luca, L. (2012) 'Methods, Formalisms and Tools for the Semantic-Based Surveying and Representation of Architectural Heritage', Applied Geomatics, (1866-9298).

Dylla, K., Frischer, B., Mueller, P., Ulmer, A. and Haegler, S. (2010) 'Rome Reborn 2.0: A Case Study of Virtual City Reconstruction Using Procedural Modeling Techniques', in Frischer, B. (ed.) Making history interactive: computer applications and quantitative methods in archaeology (CAA) ; proceedings of the 37th international conference, Williamsburg, Virginia, United States of America, March 22 - 26, 2009 BAR International Series. Oxford u.a.: Archaeopress, pp. 62-66.

Eppich, R., Chabbi, A. and Getty Conservation, I. (2007) Recording, documentation, and information management for the conservation of heritage places : illustrated examples. Los Angeles: Getty Conservation Institute.

Fai, S. and Rafeiro, J. (2014) 'Establishing an Appropriate Level of Detail (LoD) for a Building Information Model (BIM) West Block, Parliament Hill, Ottawa, Canada', ISPRS Ann. Photogramm. Remote Sens. Spatial Inf. Sci., II-5, pp. 123-130.
Fai, S., Graham, K., Duckworth, T., Wood, N. and Attar, R. (2011) 'Building Information Modelling and Heritage Documentation', XXIII CIPA International Symposium, Prague, Czech Republic, 12th-16th September.

Gandon, J. 1700s. 18th Century Section, The Four Courts. Irish Architectural Archive, Merion Square, Dublin: Irish Architectural Archive.

Garagnani, S. and Manferdini, A. M. (2013) 'Parametric Accuracy: Building Information Modeling Process Applied To The Cultural Heritage Preservation', Int. Arch. Photogramm. Remote Sens. Spatial Inf. Sci., XL-5/W1, pp. 87-92.

Gruen, A. (2012) 'Development and Status of Image Matching in Photogrammetry', The Photogrammetric Record, 27(137), pp. 36--57.

Grussenmeyer, P. and Hanke, K. (2010) 'Cultural Heritage Applications', in Maas, G.V.a.H.-G. (ed.) Airborne and Terrestrial Laser Scanning: Wittles Publishing, pp. 271-272.

Heesom, D. (2004) An Analytical System for Space Planning on Construction Sites. Doctoral Thesis, University of Wolverhampton, UK.

Hichri, N., Stefani, C., Luca, L. D. and Veron, P. 'Review of the As-Built BIM Approaches', 5th International Workshop, 3DARCH-2013. 3D Virtual Reconstruction and Visualisationof Complex Architectures, Trento, Italy, 107-112.

Hohmann, B., Krispel, U., Havemann, S. and Fellner, D. 'CityFit - High-quality urban reconstructions by fitting shape grammars to images and derived textured point clouds'. 3DARCH 2009 - 3D Virtual Reconstruction and Visualization of Complex Architectures, Trento, Italy, 25-28 February 2009.

Hong, S., Jung, J., Kim, S., Cho, H., Lee, J. and Heo, J. (2015) 'Semi-automated approach to indoor mapping for 3D as-built building information modeling', Computers, Environment and Urban Systems, 51, pp. 34-46.

Ibrahim, M. and krawczyk, R. 'The Level of Knowledge of CAD Objects within the Building Information Model', CAADRIA 2004 Conference, Seoul, South Korea.

Jung, J., Hong, S., Jeong, S., Kim, S., Cho, H., Hong, S. and Heo, J. (2014) 'Productive modeling for development of as-built BIM of existing indoor structures', Automation in Construction, 42(0), pp. 68-77.

Kelly, G. and Mccabe, H. (2006) 'A Survey of Procedural Techniques for City Generation', ITB Journal, (14), pp. 87-130.

Klein, L., Li, N. and Becerik-Gerber, B. (2012) 'Imaged-based verification of as-built documentation of operational buildings', Automation in Construction, 21(0), pp. 161-171.

Leeuwen, J. and Wagter, H. (1997) 'Architectural Design-byFeatures', in Junge, R. (ed.) CAAD futures 1997: Springer Netherlands, pp. 97-115.

Leica Geosystems. (2009) Leica TPS1200+ Series High performance Total Station. Available at: http://www.leica- 
geosystems.com/downloads123/zz/tps/tps1200/brochures/Leica _TPS1200+_brochure_en.pdf.

Lipp, M., Wonka, P. and Wimmer, M. (2008) 'Interactive Visual editing of Grammars for Procedural Architecture', ACM Transactions on Graphics, 27(3), pp. 1.

Matthews, N. A. (2008) Aerial and Close-Range Photogrammetric Technology: Providing Resource Documentation, Interpretation, and Preservation. , Denver, Colorado 80225: U.S. Department of the Interior, Bureau of Land Management, National Operations Center

Moore, N. (2013) A Model Based System For Contextual OnSite Construction Planning In Augmented Reality. Doctor of Philosophy, University of Wolverhampton, Wolverhampton.

Murphy, M. (2012) Historic Building Information Modelling (HBIM), For Recording and Documenting Classical Architecture in Dublin 1700 to 1830. Doctor of Philosphy, Trinity College Dublin, Dublin.

Murphy, M., Govern, E. M. and Pavia, S. (2013) 'Historic Building Information Modelling - Adding intelligence to laser and image based surveys of European classical architecture', ISPRS Journal of Photogrammetry and Remote Sensing, ISSN 0924-2716.

Müller, P., Wonka, P., Haegler, S., Ulmer, A. and Gool, L. V. (2006) 'Procedural Modeling of Buildings', ACM Transactions on Graphics, 25, pp. 614-623.

Müller, P., Zeng, G., Wonka, P. and Gool, L. V. (2007) 'Imagebased Procedural Modeling of Facades', ACM Trans. Graph., 26(ACM), pp. 85.

Oreni, D., Brumana, R., Della Torre, S., Banfi, F., Barazzetti, L. and Previtali, M. (2014) 'Survey turned into HBIM: the restoration and the work involved concerning the Basilica di Collemaggio after the earthquake (L'Aquila)', ISPRS Ann. Photogramm. Remote Sens. Spatial Inf. Sci., II-5, pp. 267-273.

Pauwels, P., Verstraeten, R., Meyer, R. D. and Campenhout, J. V. (2008) Architectural Information Modelling for Virtual Heritage Application. Digital Heritage -- Proceedings of the 14th International Conference on Virtual Systems and Multimedia: Archaeolingua, p. 18-23.

Previtali, M., Barazzetti, L., Brumana, R. and Scaioni, M. (2014) 'Towards automatic indoor reconstruction of cluttered building rooms from point clouds', ISPRS Ann. Photogramm. Remote Sens. Spatial Inf. Sci., II-5, pp. 281-288.

$\mathrm{Pu}, \quad \mathrm{S}$. and Vosselman, G. (2009) 'Knowledge based reconstruction of building models from terrestrial laser scanning data', ISPRS Journal of Photogrammetry and Remote Sensing, 64(6), pp. 575 - 584

Quattrini, R., Malinverni, E. S., Clini, P., Nespeca, R. and Orlietti, E. (2015) 'From TLS to HBIM. High Quality Semantically-Aware 3D Modeling of Complex Architecture', Int. Arch. Photogramm. Remote Sens. Spatial Inf. Sci., XL5/W4, pp. 367-374.
RealSIM (2013) 3D Simulation solutions for the real world. Available at: www.realsim.ie (2013).

Roche, N. (1999) The Legacy of Light, A History of Irish Windows Bray, Co. Wicklow: Wordwell Ltd., p. 14.

Royal Institute of Chartered Surveyors (2014): Measured Surveys of Land,

Buildings and Utilities, 3rd Edition. London, UK: Royal Institution of Chartered Surveyors (RICS).

Stiny, G. and Gips, J. (1972) 'Shape Grammars and the Generative Specification of Painting and Sculpture', The Best Computer Papers of 1971, pp. 125-135.

Tang, P., Huber, D., Akinci, B., Lipmand, R. and Lytle, A. (2010) 'Automatic reconstruction of as-built building information models from laser-scanned point clouds: A review of related techniques', Automation in Construction, 19(7), pp. 829-843.

Thaller, W., Krispel, U., Havemann, S., Redi, I., Redi, A. and Fellner, D. W. 'Developing Parametric Building Models - The Gandis Use Case'. 4th International Workshop 3D-ARCH 2011 , "3D Virtual Reconstruction and Visualisation of Complex Architectures", Trento, Italy, 2-4 March.

Theiler, P. W. and Schindler, K. (2012) 'Automatic Registration of Terrestrial Laser Scanner Point Clouds using Natural Planar Surfaces', ISPRS Ann. Photogramm. Remote Sens. Spatial Inf. Sci., I-3, pp. 173-178.

Thomson, C. and Boehm, J. (2015) 'Automatic Geometry Generation from Point Clouds for BIM', Remote Sensing, 7(9), pp. 11753.

Volk, R., Stengel, J. and Schultmann, F. (2014) 'Building Information Modeling (BIM) for existing buildings Literature review and future needs', Automation in Construction, 38(0), pp. 109-127.

Wang, C., Cho, Y. K. and Kim, C. (2015) 'Automatic BIM component extraction from point clouds of existing buildings for sustainability applications', Automation in Construction, 56, pp. 1-13.

Watson, A. (2009) GDL Handbook, A comprehensive Guide to Creating Powerful ArchiCAD Objects. Auckland, New Zealand: Cadimage Tools Ltd.

Wu, T. C., Lin, Y. C., Hsu, M. F., Zheng, N. W. and Chen, W. L. (2013) 'Improving Traditional Building Repair Construction Quality using Historic Building Information Modeling Concept', Int. Arch. Photogramm. Remote Sens. Spatial Inf. Sci., XL-5/W2, pp. 691-694.

Xiong, X., Adan, A., Akinci, B. and Huber, D. (2013) 'Automatic creation of semantically rich 3D building models from laser scanner data', Automation in Construction, 31(0), pp. 325-337.

Zhang, R. and Zakhor, A. 'Automatic identification of window regions on indoor point clouds using LiDAR and cameras'. Applications of Computer Vision (WACV), 2014 IEEE Winter Conference on, 24-26 March 2014, 107-114. 